\title{
Patterns of Neglect Dissociation
}

\author{
CRISTINA BARBIERI and ENNIO DE RENZI
}

Clinica Neurologica, Ospedale Policlinico, Via del Pozzo 71, 41100 Modena, Italy

\begin{abstract}
Extinction in the visual, tactile and auditory modality, and visual, tactile and motor neglect were investigated in 40 right brain-damaged (RBD) and 50 left brain-damaged (LBD) patients. The presence of neglect was assessed with reference to the performance of 50 control patients. Visual neglect was only found in RBD patients and its severity could vary from one test to another. Tactile neglect was much rarer and it occurred with lesions in either hemisphere. Five cases of motor neglect were found in patients with right parietal damage. Both extinction and neglect could be present either confined to 1 modality or involving 2 or more. The assumption that extinction always represents an attenuated form of neglect was challenged by the finding of 1 patient with visual neglect but no visual extinction and of 3 patients with extinction in all modalities and no sign of neglect. Exploration of contralateral space would appear to be a process monitored by mechanisms decentralized at the level of the single modality rather than by a supramodal supervisor.
\end{abstract}

\section{Introduction}

Current knowledge on unilateral neglect in right brain-damaged (RBD) patients is based mainly on its manifestations in the sphere of vision, where it becomes apparent as failure to orient and respond to stimuli lying in the left half of space. A variety of tasks have been used to measure its presence and severity, but little is known about their relative sensitivity. Neglect in other sensory modalities has been rarely studied and there is uncertainty about what are the best ways to test for it.

Manual exploration of the environment in search of a target, without the aid of vision, has been used to investigate tactile neglect: a reluctance to move into the left space has been reported in RBD patients in 3 studies (Chedru, 1976; De Renzi et al., 1970; Weintraub and Mesulam, 1987), but not in a fourth one (Villardita, 1987), where RBD patients with visual neglect were found to search preferentially the target in the contralateral space. A different procedure has been adopted by Halsband et al. (1985) who required their RBD patients to perform a texture discrimination test with the right hand placed either in the left or right side of space and took a larger number of errors when the hand was to the left as evidence of neglect. The relation of this type of performance to hemi-inattention for left-sided stimuli is, however, not altogether clear.

Whether neglect also occurs in the auditory modality is unknown. Complete unresponsiveness to sounds coming from the left space has never 
been reported, except in conditions of double simultaneous stimulation, where extinction of the left stimulus is sometimes seen. Extinction is often considered an attenuated form of neglect, but there is evidence (De Renzi $e t$ al., 1984) that in some cases it may be contingent on disruption of the auditory pathways. In the other sensory modalities the relation of extinction to neglect has never been investigated systematically and we do not know, therefore, whether the claim that the two phenomena lie along a continuum is justified in every case.

The term neglect has also been used to label a disorder of motor behaviour characterized by the tendency not to use the limbs contralateral to the lesion, in spite of the absence of paresis. These patients show a dissociation between the normal strength exerted with these limbs when attention is explicitly drawn to them, and the failure to use them spontaneously in gesturing, bimanual tasks and even automatic movements, as, for instance, when the patient "forgets" the lower limb on the bed when trying to get up. It is worth emphasizing that in this case the disorder concerns the contralateral side of body and not the contralateral environment and it is, therefore, open to question to what extent motor and sensory neglect pertain to the same order of phenomena.

The aim of the present research was to gain a comprehensive view of the degree of association or dissociation underlying the spectrum of symptoms covered under the heading of neglect. Patients with unilateral brain damage were tested for the presence of extinction, sensory neglect and motor neglect with a view to ascertaining whether these phenomena reflect the disruption of a single, supramodal apparatus, or of discrete, modality-specific mechanisms.

\section{Methods}

Patients

Candidates for the present study were right-handed patients hospitalized in the neurological wards during the period 4 October 1983 to 11 December 1985 who could cooperate in testing. Ninety patients were investigated, 40 with right brain damage (RBD) and 50 with left brain damage (LBD). The side and locus of the cerebral lesion was ascertained based on CT scan findings. Forty patients with a lesion below the cervical spine made up the control group.

TABle 1. Demographic and etiology data

\begin{tabular}{lcccccc}
\hline & & & \multicolumn{3}{c}{ Etiology } \\
\cline { 4 - 6 } & $\begin{array}{c}\text { Age } \\
(y r s)\end{array}$ & $\begin{array}{c}\text { Educational } \\
\text { level } \\
(y r s)\end{array}$ & $V$ & $\mathcal{N}$ & $I$ \\
\hline LBD patients (No.: 50) & $60 \cdot 7$ & $6 \cdot 37$ & 39 & 11 & 0 \\
RBD patients (No.: 40) & $57 \cdot 8$ & $7 \cdot 67$ & 28 & 11 & 1 \\
Control patients (No.: 49) & 58.6 & 5.35 & & & \\
\hline
\end{tabular}

$\mathrm{V}=$ vascular; $\mathrm{N}=$ neoplastic $; \mathrm{I}=$ infectious. 
Table 1 shows the etiology, age and educational level of the patients. No inter-group difference was significant.

The tasks that required a motor response were carried out by the braindamaged patients with the hand ipsilateral to the side of the lesion. Half the controls used the right hand and half the left hand.

\section{Tests}

Visual neglect

\section{Reading test}

The patient was presented with a cardboard sheet, $41 \mathrm{~cm} \times 29.5 \mathrm{~cm}$, where the sentence La pera e' caduta sotto l'albero ('The pear has fallen under the tree"), was written in $15 \mathrm{~mm}$ high Letraset letters on a single line, $38.5 \mathrm{~cm}$ long. The patient was requested to read it aloud. Aphasics were encouraged to attempt reading, not worrying about the errors they might make. If reading proved to be impossible, they were requested to point to each word of the sentence. Two LBD patients were, by oversight, not tested. The sentence has 3 words lying to the left (La pera e'), 1 in the centre (caduta) and 3 to the right (sotto l'albero).

\section{Circle test}

A white cardboard sheet, $70 \times 50 \mathrm{~cm}$, displaying 10 red circles, $15 \mathrm{~mm}$ in diameter, symmetrically arranged, 5 in the left half and 5 in the right half, was presented for the patient to point to the circles with the forefinger ipsilateral to lesion.

\section{Picture test}

The patient was given a white cardboard sheet, $70 \times 50 \mathrm{~cm}$, displaying 9 pictures, $5 \times 4 \mathrm{~cm}$, arranged in 3 columns and was requested to name or, if severely aphasic, to point to all of the picture $s /$ he saw with the forefinger ipsilateral to lesion. Four LBD patients and 1 RBD patient were not tested.

\section{Cookie theft picture}

Patients were presented with the cookie theft picture from the Boston Aphasia Test (Goodglass and Kaplan, 1972) and were requested to describe as accurately as possible what they saw, or, if severely aphasic, to point to the individual elements of the drawing. Four elements were identified as salient in the left half of the picture (girl, cookie jar, stool, boy) and 5 in the right half (mother, dish, sink, window, cups). The test was given to all controls, to $43 \mathrm{LBD}$ (the remaining 7 being too severely aphasic to be tested) and to $39 \mathrm{RBD}$ patients.

\section{Tactile neglect}

The patient was blindfolded and presented with a wooden board, $60 \times 40 \mathrm{~cm}$, where 9 circular wells, $3.5 \mathrm{~cm}$ in diameter and $1 \mathrm{~cm}$ deep were 
arranged in 3 columns: to the left, in the centre and to the right. The distance between adjacent columns was $85 \mathrm{~mm}$. The board was positioned on the desk so that the central column corresponded to the patient's sagittal midplane. In each well there was a marble that the patient had to pick up. S/ he was not told the number of wells, but knew the size of the board, because the examiner had previously guided her/his hand around its borders. Time limit: 2 minutes. Four LBD and 2 RBD patients were not tested.

\section{Motor neglect}

Motor neglect was evaluated by observing the patient's spontaneous behaviour and her/his performance on the following 4 tasks, requiring bimanual coordination.

\section{Alternating movements}

The patient had to tap simultaneously the table with the clenched fist of one hand and the outstretched fingers, palm down of the other hand, and then to invert the position of the hands. 'The sequence had to be repeated 3 times.

\section{Envelope and letter}

The patient was requested to fold a written sheet and to insert it into an envelope.

\section{Bolt and nut}

The patient had to screw a nut onto a bolt.

\section{Playing cards}

The patient had to shuffle and deal playing cards. Only patients without motor defects preventing the utilization of both limbs were eligible for this test. They were $31 \mathrm{RBD}, 42 \mathrm{LBD}$ and all of the controls.

\section{Extinction in the 3 modalities}

Only patients with no or mild contralateral sensory impairment were tested. In the latter case, the stimulus intensity was always such as to make it easily perceivable when delivered unilaterally.

\section{Visual extinction}

The confrontation method was used. The examiner kept his closed fists first in the upper and then in the lower quadrants and rapidly flicked his forefinger out either to the left or to the right or to both sides. Five left, 5 right and 5 bilateral stimuli were given in a random order. Extinction was considered present when unilateral stimuli were all perceived and the stimuli contralateral to lesion were missed more than twice on double simultaneous stimulation. 


\section{Tactile extinction}

The patient was touched on his/her hands by the examiner, who delivered 5 bilateral stimuli intermingled with 10 unilateral stimuli, 5 to the left and 5 to the right. Responses were given by moving or naming the touched hand. Extinction was considered present when more than 2 of the 5 bilateral stimuli were not detected on the contralateral side, the unilateral stimuli being all perceived.

\section{Auditory extinction}

Stimuli were delivered with 2 sound generators $(75 \mathrm{~dB})$, kept manually at a distance of approximately $5 \mathrm{~cm}$ from the ears, and activated by pushing a button. Five bilateral stimuli were administered, intermingled with 10 unilateral stimuli, 5 to the right and 5 to the left ear. Responses were given by pointing with the forefinger to the ear stimulated. No testable patient found it difficult to identify unilateral stimuli, but $1 \mathrm{RBD}$ patient displaced systematically the left stimuli to the right ear. Extinction was considered present when more than 2 of the 5 bilateral stimuli were missed on the same side.

\section{Results \\ Visual neglect}

A few control patients occasionally neglected a stimulus on 1 test, but never on 2 or more tests. More specifically, 1 control patient omitted the initial article "la" on the reading test, 4 control patients omitted a circle on the circle test (in 2 cases it was located in the left half and in 2 cases in the right half of the cardboard) and 1 patient a left-sided figure on the picture test. On the cookie theft test no control patient omitted all of the details lying on the left side of the picture and, in particular, they always mentioned the girl, who is the leftmost figure.

Brain-damaged patients were considered affected by neglect if they omitted at least 1 stimulus on more than 1 test or more than 1 stimulus on a single test. There were 2 LBD patients who showed minimal signs of right hemi-inattention, in that they neglected 1 stimulus on both the circle and the picture test. This contrasted with the presence of substantial signs of neglect in $13 \mathrm{RBD}$ patients, whose omissions are summarized by Table 2. The severity of the deficit ranged from patients who only omitted the leftmost stimuli (patient no. 9) to those who neglected all of the stimuli, except the rightmost ones (patient no. 21). The 2 tests most sensitive to neglect were sentence reading and picture description, where 10 patients made a pathological number of omissions. The corresponding figures for the circle and the picture test were 7 and 5 patients, respectively. It is worth noting that in a few patients the severity of neglect varied remarkably from test to test: patient no. 15, for example, read only the last word of the sentence but showed no sign of neglect on the remaining 3 tests, while patient No. 4 read the entire sentence, but omitted 3 left-sided stimuli on the picture test and all of the left-sided stimuli plus the mother figure on the cookie theft picture. 
TABLE 2. The stimuli omitted by RBD patients on the visual tests

\begin{tabular}{lllll}
\hline $\begin{array}{llll}\text { Patient } \\
\text { No. }\end{array}$ & Sentence & Circles & Pictures & Cookie theft \\
\hline 1 & La pera e' caduta & $3 \mathrm{~L}$ & $\mathrm{NT}$ & left + mother \\
3 & La pera & $1 \mathrm{~L}$ & $1 \mathrm{~L}$ & left \\
4 & - & $1 \mathrm{~L}$ & $3 \mathrm{~L}$ & left + mother \\
5 & La pera e' & $2 \mathrm{~L}$ & - & - \\
6 & La pera e' caduta sotto & $1 \mathrm{~L}$ & $3 \mathrm{~L}+1 \mathrm{R}$ & - \\
9 & La & & $1 \mathrm{~L}$ & girl \\
12 & La pera e' & $1 \mathrm{~L}+1 \mathrm{R}$ & $1 \mathrm{~L}$ & left \\
15 & La pera e' caduta sotto l' & - & $1 \mathrm{R}$ & - \\
18 & La pera e' caduta & $2 \mathrm{~L}$ & $1 \mathrm{~L}$ & left \\
21 & La pera e' caduta sotto l' & $5 \mathrm{~L}+2 \mathrm{R}$ & $3 \mathrm{~L}$ & left + mother \\
28 & & $2 \mathrm{~L}$ & $1 \mathrm{R}$ & girl \\
29 & La pera e' caduta & $5 \mathrm{~L}$ & $3 \mathrm{~L}$ & left + mother \\
32 & La pera e' & $5 \mathrm{~L}+2 \mathrm{R}$ & $3 \mathrm{~L}$ & left + mother \\
\hline
\end{tabular}

NT: not tested; L: left; R: right: -..-: flawless performance; left: all left-sided figures neglected.

\section{Tactile neglect}

Seven control patients (4 using the right hand and 3 the left hand) failed to recover all the marbles, but they never omitted more than 1 marble per column. Neglect was considered present in a brain-damaged patient when more than 1 omission occurred in the column contralateral to lesion. There were 5 such patients, 2 with left hemisphere lesion, showing right neglect and 3 with right hemisphere lesion showing left neglect. Table 3 reports the number of marbles omitted in each column by the control and braindamaged patients.

Tactile neglect bears little, if any, relation to visual neglect. Not only the 2 left brain-damaged patients with neglect, but also the right braindamaged patient (no. 11) who omitted all of the marbles of the left column were free from signs of visual hemi-inattention and, conversely, the 2 patients (no. 21 and 32) with the severest manifestations of visual neglect passed the tactile test flawlessly.

\section{Motor neglect}

Definite manifestations of motor neglect in the left upper limb contralateral to the lesion were absent in LBD patients and present in 5 out of the 28 RBD patients who had mild or no paresis and could therefore be tested. Three of them (no. 1, 7 and 29) did not spontaneously use their left hand, when attempting to fold the sheet and to insert it into the envelope, to screw the nut on the bolt, to dial cards and performed the alternate movement task without moving the left hand. When requested to raise the upper limbs, they raised only the right one, but when the command was "raise your left limb", they carried it out correctly. One patient "forgot" his lower limb on the bed when trying to get up and another completely lacked the placing reaction. 
TABLE 3. Tactile neglect. Number of marbles that patients did not find in the left $(\mathbf{L})$, central $(\mathbf{C})$ and right $(\mathbf{R})$ columns

\begin{tabular}{|c|c|c|c|c|c|c|c|c|c|c|c|}
\hline \multirow[b]{2}{*}{ Pt. No. } & \multicolumn{3}{|c|}{ Controls } & \multirow[b]{2}{*}{ Pt. No. } & \multicolumn{3}{|c|}{$L B D$ patients } & \multirow[b]{2}{*}{ Pt. No. } & \multicolumn{3}{|c|}{$R B D$ patients } \\
\hline & $L$ & C & $R$ & & $L$ & $C$ & $R$ & & $L$ & C & $R$ \\
\hline 2 & $*$ & & & 40 & $*$ & & $* * *$ & 3 & $* *$ & $*$ & \\
\hline 17 & $*$ & * & $*$ & 41 & & & $* *$ & 11 & $* * *$ & & \\
\hline 24 & $*$ & & & & & & & 18 & $* *$ & & \\
\hline 34 & & $*$ & & & & & & & & & \\
\hline 14 & & * & & & & & & & & & \\
\hline 25 & $*$ & & $*$ & & & & & & & & \\
\hline 37 & $*$ & & & & & & & & & & \\
\hline
\end{tabular}

The remaining 2 patients (No. 3 and 5) did not use the left hand in 2 of the tasks and in the alternating movements. The clinical features of these patients are reported in Table 4. All had a lesion centred on the posterior parietal lobe. Neither somatosensory nor visual field deficits were a constant accompaniment of motor neglect. Visual hemi-inattention was severe in 3 patients (No. 1, 3, 29), mild in patient No. 5 and absent in patient No. 7, while tactual search carried out with the healthy hand showed neglect in only 1 case (No. 3). On the other hand, 3 patients with severe visual hemiinattention and 2 patients with tactile neglect showed no sign of motor neglect.

\section{Extinction and its relation to neglect}

Extinction could only be tested in patients who did not show moderate to severe visual or tactile deficit on single stimulation. The upper part of Table 5 reports the number of patients testable with double simultaneous stimulation (DSS) for each modality. One RBD patient could not be tested in the auditory modality, because he consistently showed displacement of the left ear stimulus to the right ear on single stimulation. The incidence of visual

TABLE 4. Clinical signs of patients showing motor neglect

\begin{tabular}{|c|c|c|c|c|c|c|c|c|}
\hline \multirow[b]{2}{*}{ Pt. No. } & \multirow[b]{2}{*}{$\begin{array}{l}\text { Sensory } \\
\text { deficit }\end{array}$} & \multirow[b]{2}{*}{$V F D$} & \multicolumn{3}{|c|}{ Extinction } & \multirow[b]{2}{*}{$\begin{array}{l}\text {-Visual } \\
\text { neglect }\end{array}$} & \multirow[b]{2}{*}{$\begin{array}{l}\text { Tactile } \\
\text { neglect }\end{array}$} & \multirow[b]{2}{*}{ Locus of lesion } \\
\hline & & & $V$ & $T$ & $A$ & & & \\
\hline 1 & - & Mild & + & + & + & Severe & - & Par.-Occ. haematoma \\
\hline 3 & Severe & Mild & + & $?$ & - & Severe & + & Par. infarct \\
\hline 5 & - & Mild & + & - & + & Mild & - & Post. Par. infarct \\
\hline 7 & Moderate & Mild & + & + & + & - & - & Par. metastasis \\
\hline 29 & Moderate & - & + & + & - & Severe & - & Par.-Occ. tumour \\
\hline
\end{tabular}

V: visual; T: tactile; A: auditory; Par.: parietal; Occ.: occipital; Post.: posterior; + : present; - : absent; ?: not testable. 
TABLE 5. Incidence of extinction

(a) Number of patients extinguishing in each modality

\begin{tabular}{|c|c|c|c|c|c|c|}
\hline & \multicolumn{3}{|c|}{ RBD patients (40) } & \multicolumn{3}{|c|}{$L B D$ patients $(50)$} \\
\hline & $V$ & $T$ & $A$ & $V$ & $T$ & $A$ \\
\hline Testable & 34 & 33 & 39 & 43 & 46 & 50 \\
\hline Extinguishing & 15 & 17 & 19 & 3 & 6 & 6 \\
\hline
\end{tabular}

(b) Patterns of extinction in patients testable in all modalities

\begin{tabular}{lcccccccc}
\hline & $\mathcal{N} E$ & $V$ & $T$ & $A$ & $V T$ & $V A$ & $T A$ & $V T A$ \\
\hline RBD patients (No.: 30) & 18 & 2 & 0 & 1 & 4 & 2 & - & 3 \\
LBD patients (No.: 39) & 31 & 3 & 1 & 2 & - & 0 & 2 & - \\
\hline
\end{tabular}

NE: not extinguishing; V: visual; T: tactile; A: auditory.

extinction was higher in RBD patients than in LBD patients (chi square: $12.60 ; p<0.01)$; no significant difference was found in the tactile and auditory modality. The lower part of Table 4 shows how many of the patients testable in all modalities manifested extinction in one or more modalities. There were $3 \mathrm{RBD}$ patients who extinguished in all modalities (VTA), 4 in the visual and tactile (VT) modality and 2 in the visual and acoustic (VA) modality. Two LBD patients had TA extinction.

Of the 3 RBD patients who extinguished in all modalities 1 (no. 1) showed visual neglect but not tactile neglect, 1 (no. 11) tactile neglect, but not visual neglect, while no evidence of neglect was present in the third patient (no. 40). On the other hand, there was $1 \mathrm{RBD}$ patient (no. 15) who evinced severe neglect on reading (only the rightmost word was perceived) and yet had no extinction in any modality.

Of the 5 patients with tactile neglect, 4 could not be tested for tactile extinction, because of sensory deficit. The fifth patient (RBD patient no. 11) extinguished on the left hand.

\section{Discussion}

Inattention to left space following right brain damage is preferentially detectable in the visual modality where it occurs in approximately one-third of patients. Its severity ranges from cases in which omissions affect the leftmost stimuli to cases where they extend to central stimuli and even to those lying in the left portion of the right hemispace. It follows that taking as an index of left neglect only omissions confined to that side or excluding cases with additional right-sided omissions, or subtracting right-sided omissions from left-sided omissions (Albert, 1973; Halsband et al., 1985; Weintraub and Mesulam, 1987) may lead to an underestimation of the phenom- 
enon, which in the most severe cases goes beyond the midline and involves the left half of the right hemispace as well. This behaviour was particularly apparent in sentence reading and picture description, which were, generally speaking, the tasks most sensitive to neglect.

There was, however, no single test which was superior to others in every case, as shown by the few patients whose neglect was missed by the reading test and detected by pointing tests. Whether the variability in visual test performance is task dependent or contingent upon attention fluctuation is a question that can be answered by investigating how consistent across trials is the order of difficulty of tests in the single patient. A patient showing a striking dissociation between left-sided neglect for letter reading and rightsided neglect for copying drawings and bisecting lines has been reported (De Lacy Costello and Warrington, 1987). As a practical outcome of the present research, it is recommended that patients with hemi-inattention defects should be tested with a number of tests.

Compared to visual neglect, tactile neglect turned out to be a rather infrequent phenomenon, not closely associated with right brain damage. It occurred in $7.5 \%$ of right brain-damaged patients and $4 \%$ of left braindamaged patients. The right hemisphere percentage was considerably lower than that (24\%) reported in 2 previous studies (Chedru, 1976; De Renzi et al., 1970). The difference is most likely to be due to the features of the tasks and the way the performance was scored. Our current test was constructed on the analogy of the visual pointing tasks and the progressive displacement of the exploring hand to the left was favoured by the regular arrangement of the holes and the short distance between them. In contrast, De Renzi et al.'s (1970) patients had to travel through the alleys of an unknown maze in search of a marble located at the end of one of the 4 lateral arms; Chedru's (1976) patients had to tap the keys of a teletype keyboard "in any manner they wished". In these conditions space exploration is left to the initiative of the patient and his/her reluctance to operate in the left space is not countermanded by instruction or task promptings.

It may be observed that the present test as well as those described in the literature are called tactile, because it is the information collected through the somesthetic modality that permits the recovery of the target. None the less, it is likely that a visual representation of space also plays a role in guiding the exploring hand. Be that as it may, the finding that tactile neglect also occurred in 2 left brain-damaged patients and 1 right brain-damaged patient who were not hemi-inattentive in the visual modality, and was absent in patients with severe visual neglect points to discrete mechanisms subserving the tactile and visual exploration of space. Chedru (1976) too provided evidence for dissociation of function: visual neglect preferentially affected patients with damage to either hemisphere and visual field defect; tactile neglect preferentially affected right brain-damaged patients without visual field defect.

The present findings are in agreement with some data in the literature in that they challenge the view that motor neglect bears a close relationship to sensory manifestations of neglect. This peculiar symptom of motor neglect is 
not consistently associated with visual or tactile neglect or with disorders of body awareness. Its occurrence suggests the existence of an autonomous mechanism that integrates sensory and motivational inputs in order to trigger limb motility. Its disruption blocks the activation of motor areas, unless attention is called to the involved limbs through verbal command. In the present series the lesion always involved the posterior parietal lobe, but the literature reports cases of motor neglect following damage to the frontal lobe (Castaigne et al., 1972; Laplane and Degos, 1983), the thalamus (Cambier et al., 1980; Castaigne and Cambier, 1969; Laplane et al., 1982; Schott $e t$ al., 1981) and the caudate nucleus plus the anterior limb of the internal capsule (Valenstein and Heilman, 1981). Laplane and Degos (1983), who published the largest series of patients with motor neglect, reported 12 cases with right hemisphere damage and 8 cases with left hemisphere damage, but stated that, had they included patients with both motor and sensory neglect, the prevalence following right-sided lesion would have been much more marked. We only found motor neglect in right braindamaged patients.

The systematic investigation of extinction in the 3 sensory modalities has confirmed what clinical experience suggests, namely, that extinction can be confined to 1 modality or involve 2 or all of them in any possible combination. Visual extinction occurred more frequently in RBD patients than in LBD patients, an asymmetry apparently supportive of the relation of the phenomenon to neglect, which must, however, be considered with caution. Previous studies (De Renzi et al., 1984; De Renzi et al., 1986) pointed out a possible bias in hemispheric sample selection, due to the $a$ priori exclusion from the investigation of the most severe aphasics because of their inability to understand test instruction. Moreover, no significant difference between the hemispheric groups was found in the tactile and auditory modality (the latter finding is in agreement with previous data (De Renzi et al., 1984)). The assumption that extinction bears a close relation to neglect, representing a minor manifestation thereof, would entail 2 predictions: that patients with extinction in every modality should manifest at least some signs of neglect and that every patient with neglect should show extinction in the corresponding modality. Both contentions are questioned by our data. One of the $3 \mathrm{RBD}$ patients who extinguished in all of the 3 modalities completed without omissions both the visual and tactile searching tests. On the other hand, patient no. 15, who had a right posterior cerebral artery infarct with upper quadrantopia, read the last word of the sentence only, but never extinguished in the lower quadrants. These findings concur with those of Weintraub and Mesulam (1987) and caution against establishing an unequivocal relationship between extinction and neglect. They also emphasize the need for a careful analysis in the single case of the elements discriminating the sensorial from the attentional origin of extinction.

In conclusion, the outcome of the present research suggests that the gamut of deficits covered by the concept of neglect do not constitute a unitary, coherent syndrome, which can be traced back to the disruption of a supramodal supervisor, controlling the deployment of attention to contrala- 
teral space. The finding that every type of dissociation among neglect phenomena may occur (Halsband et al., 1985) is more supportive of a model that envisages discrete attentional mechanisms operating independently and which may be disrupted separately or in association, depending on the site and size of lesion. A multicentric model of attention has already been proposed to account for the independence of peripersonal and extrapersonal neglect in the monkey (Rizzolatti et al., 1985) and the dissociation between unawareness for hemiplegia and hemianopia in RBD patients (Bisiach et al., 1986). Based on the dissociation between the 2 forms of anosognosia and between anosognosia for hemianopia and visual neglect, Bisiach et al. (1986) argued that neglect phenomena represent "local failure of a relatively peripheral stage of information processing". One may wonder whether the term attention, with its general semantic implications, is the most appropriate to account for these function-specific phenomena, and we believe a more differentiated analysis of neglect needs to be considered.

\section{Acknowledgments}

This work was supported by a grant from the Consiglio Nazionale delle Ricerche and a grant from the Ministero della Pubblica Istruzione to Dr E. De Renzi.

\section{References}

Albert, M. L. (1973). A simple test of visual neglect. Neurology, 23, 658-664.

Bisiach, E., Vallar, G., Perani, D., Papano, C. and Berti, A. (1986). Unawareness of disease following lesions of the right hemisphere: Anosognosia for hemiplegia and anosognosia for hemianopia. Neuropsychologia, 24, 471-482.

Cambier, J., Elghozi, D. and Strube, E. (1980). Trois observations de lésions vasculaires du thalamus droit avec syndrome de l'hémisphère mineur. Discussion du concept de négligence thalamique. Revue Neurologique, 136, 105-116.

Castaigne, P. and Cambier, J. (1969). La semeiologie des lésions thalamiques. Presse Médicale, 77, 1101-1105.

Castaigne, P., Laplane, D. and Degos, J. D. (1972). Trois cas de négligence motrice par lésion frontale prerolandique. Revue Neurologique, 126, 5-15.

Chedru, F. (1976). Space representation in unilateral spatial neglect. Fournal of Neurology, Neurosurgery and Psychiatry, 39, 1057-1061.

De Lacy Costello, A. and Warrington, E. K. (1987). The dissociation of visuospatial neglect and neglect dyslexia. Journal of Neurology, Neurosurgery and Psychiatry, 50, 1110-1116.

De Renzi, E., Faglioni, P. and Scotti, G. (1970). Hemispheric contribution to exploration of space through the visual and tactile modality. Cortex, 6, 191-203.

De Renzi, E., Gentilini, M. and Pattacini, F. (1984). Auditory extinction following hemisphere damage. Neuropsychologia, 22, 733-744.

De Renzi, E., Gentilini, M. and Bazolli, C. (1986). Eyelid movement disorders and motor impersistence in acute hemisphere disease. Neurology, 36, 414-418.

Goodglass, H. and Kaplan, E. (1972). "The Assessment of Aphasia and Related Disorders". Lea \& Febiger, Philadelphia.

Halsband, U., Gruhn, S. and Ettlinger, G. (1985). Unilateral spatial neglect and defective performance in one half of space. International Journal of Neuroscience, 28, 173-195. 
Laplane, D. and Degos, J. D. (1983). Motor neglect. Fournal of Neurology, Neurosurgery and Psychiatry, 46, 152-158.

Laplane, D., Escourolle, R., Degos, J. D., Sauron, B. and Massiou, H. (1982). La négligence motrice d'origine thalamique. Revue Neurologique, 138, 201--211.

Rizzolatti, G., Gentilucci, M. and Matelli, M. (1985). Selective spatial attention: one center, one circuit, or many circuits? In "Attention and Performance XI" (Eds. M. I. Posner and O. S. M. Marin). Erlbaum, N.J.

Schott, B., Laurent, B., Mauguiere, F. and Chazot, G. (1981). Négligence motrice par hématome thalamique droit. Revue Neurologique, 137, 447-455.

Valenstein, E. and Heilman, K. M. (1981). Unilateral hypokinesia and motor extinction. Neurology, 31, 445-448.

Villardita, C. (1987). Tactile exploration of space and visual neglect in brain-damaged patients. Fournal of Neurology, 234, 292-297.

Weintraub, S. and Mesulam, M. M. (1987). Right cerebral dominance in spatial attention. Further evidence based on spatial neglect. Archives of Neurology, 44, 621 625. 


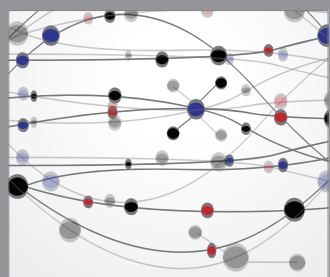

The Scientific World Journal
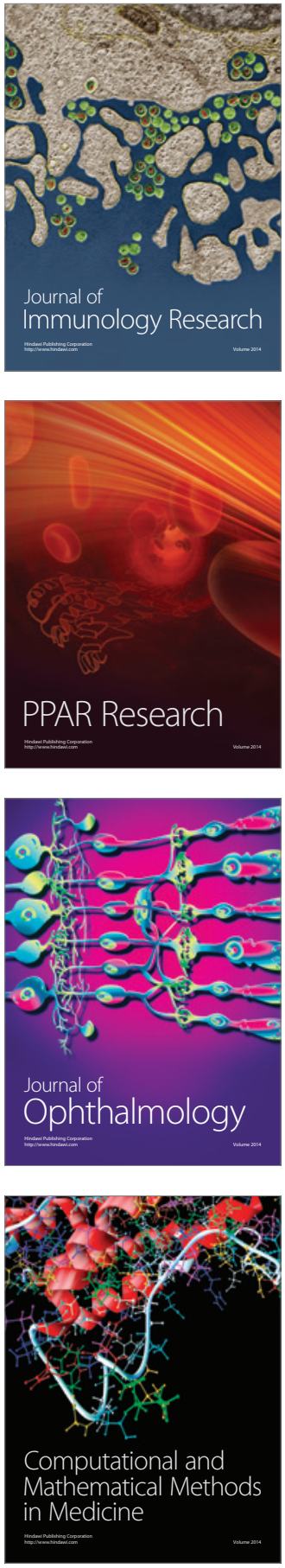

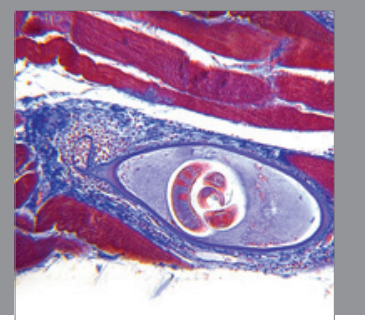

Gastroenterology

Research and Practice
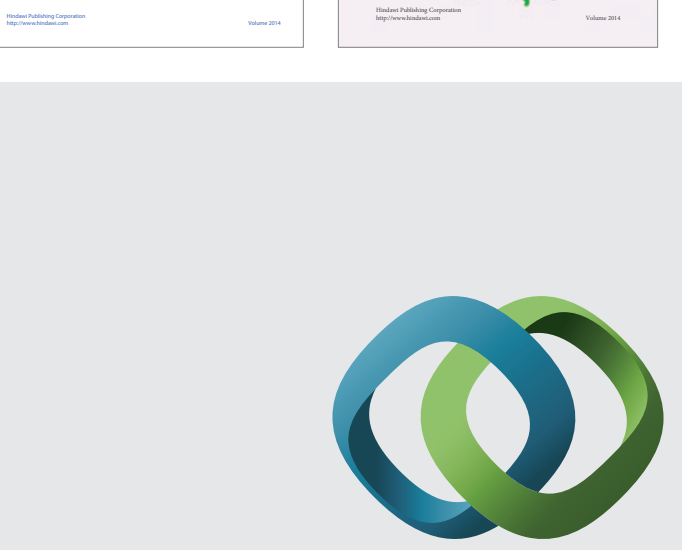

\section{Hindawi}

Submit your manuscripts at

http://www.hindawi.com
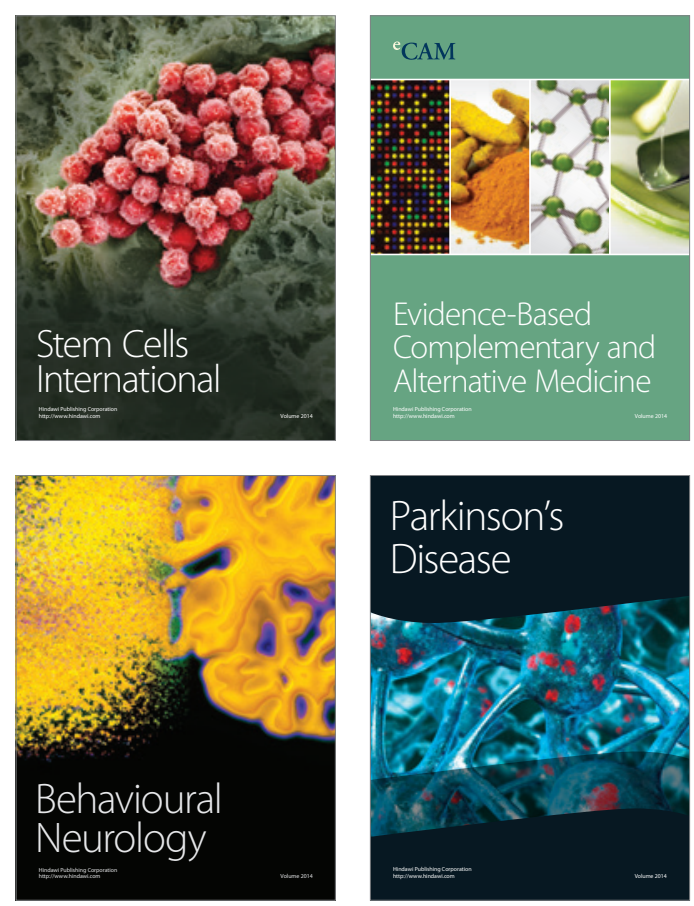

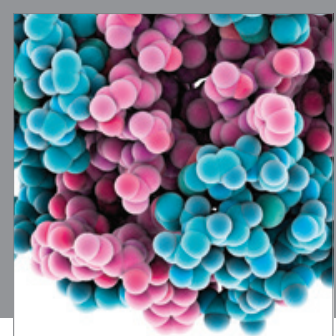

Journal of
Diabetes Research

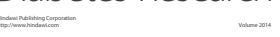

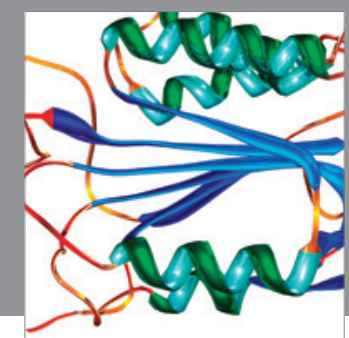

Disease Markers
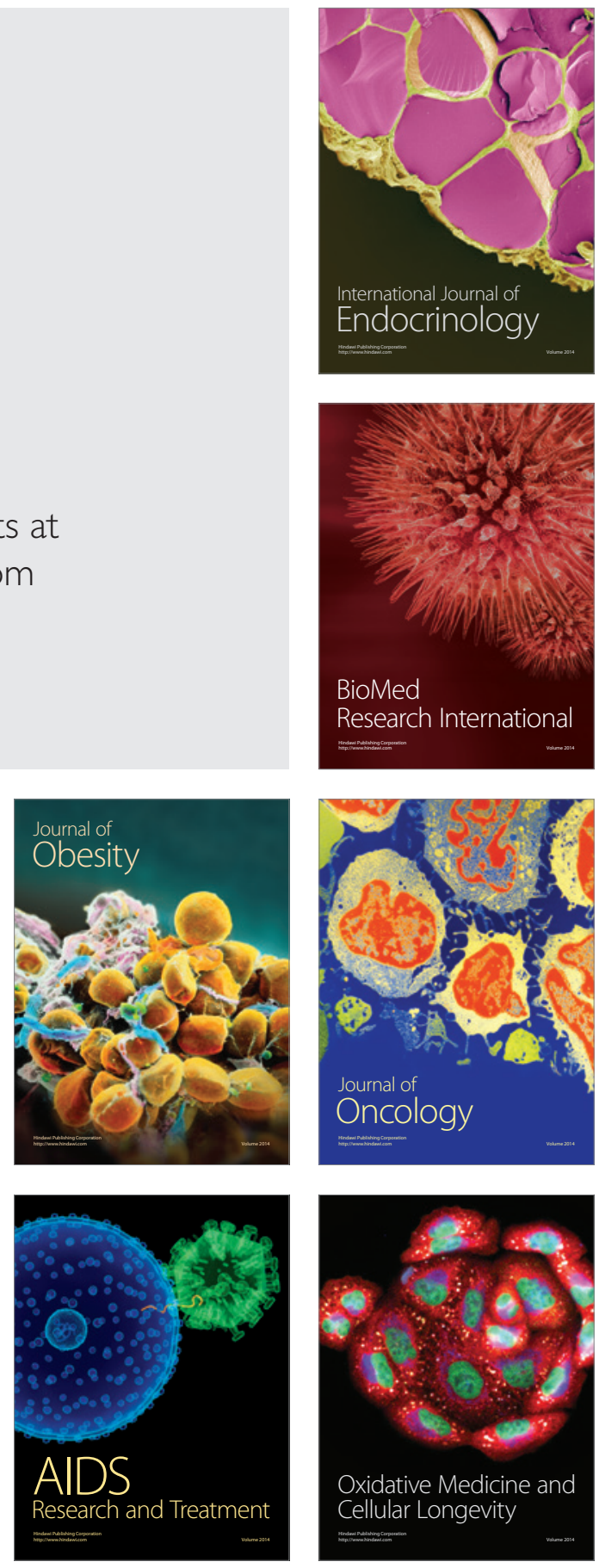